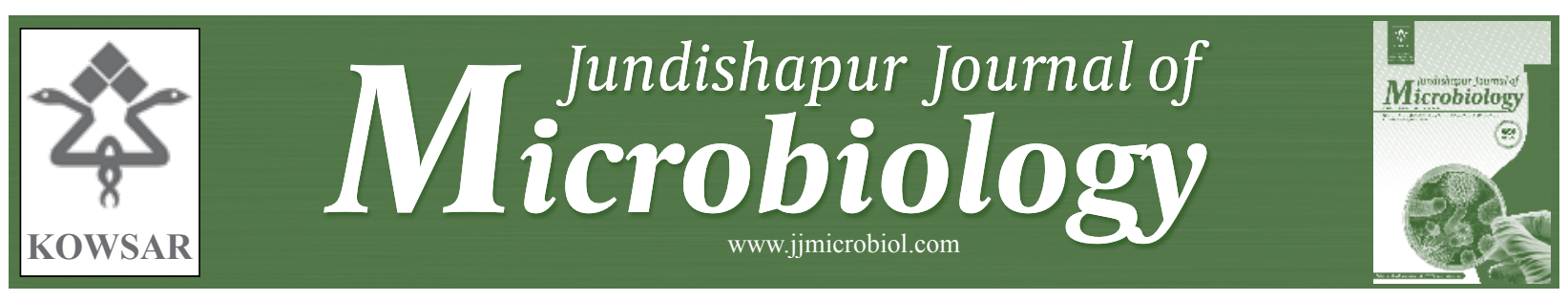

\title{
Cloning and Sequencing of Iranian Chicken Interleukine-2 Gene
}

\author{
Hamideh Amini ${ }^{1^{*}}$, Seyed Davood Hoseini ${ }^{2}$, Jamileh Nowroozi ${ }^{1}$, Delavar Shahbazzadeh ${ }^{3}$ \\ ${ }^{1}$ Department of Microbiology, Faculty of Biology, Islamic Azad University, Tehran Branch, Tehran, IR Iran \\ ${ }^{2}$ Department of Cellular And Molecular Biology, Razi vaccination and serum research institute, Arak, IR Iran \\ ${ }^{3}$ Department of Biotechnology, Pasteur institute, Tehran, IR Iran
}

A R T I C L E I N F O

Article type:

Original Article

\section{Article history:}

Received:10 Apr 2011

Revised: 15 Nov 2011

Accepted:1 Dec 2011

Keywords:

Chicken

Interleukin

Recombinant protein

Cytokine

Gene

\begin{abstract}
A B S T R A C T
Background: : IL-2 is a cytokine that plays an active role in the activation and maintenance of both acquired and innate immune defenses. It is also capable of improving the protective immune responses that are generated by conventional vaccines against avian pathogens in the poultry industry when used as an adjuvant.

Objectives: The aim of this study was to extract and sequence Iranian chicken IL-2.

Materials and Methods: In this study, genomic DNA was extracted from Iranian chickens. Total RNA was isolated by culturing harvested splenocytesand lysing them with Trizol reagent per the manufacturer's instructions. mRNA was isolated and converted to cDNA using reverse-transcriptase (RT) and specific designed primers. Then, the PCR product was ligated into the PTZ57R/T plasmid (TA-cloning) and transformed into competent Top10 E. coli cells.

Results: A unique 668-bp band was obtained after RT-PCR. Restriction enzyme digestion and colony PCR analysis and direct sequencing confirmed the existence of the desired gene in transformants.

Conclusions: For first time in Iran, the chIL-2 gene was successfully extracted, cloned, and transferred into E. coli. The efficacy of recombinant or DNA vaccines can be modulated by codelivery of this cytokine gene.
\end{abstract}

Copyright $\odot 2012$ Kowsar Corp. All rights reserved.

- Implication for health policy/practice/research/medical education:

The ability of chIL-2 to enhance T-cell activation and proliferation suggests that it augments the immune response when used as an adjuvant.

Please cite this paper as:

Amini H, Hoseini SD, Nowroozi J, Shahbazzadeh D. Cloning and Sequencing of Iranian Chicken Interleukine-2 Gene. Jundishapur J Microbiol.2012;5(3): 502-6. DOI: 10.5812/jjm.3636

\section{Background}

In the past 2 decades, the poultry broiler industry has grown astonishingly; almost 40 billion birds are hatched worldwide annually. This highly profitable industry provides approximately $40 \%$ off all consumed meat, with a $\$ 150$ billion per annum retail market, and supplies a multibillion dollar poultry health market. Since chickens are grown under forceful conditions, they are more susceptible to infectious diseases. These diseases can cause

\footnotetext{
* Corresponding author: Hamideh Amini, 15th kilometer Arak-Ghom Highway, Razi Vaccine and Serum research institute (Arak Branch), Arak, IR Iran. Tel:+98-8613544702, Fax:+98-8613544704, E-mail: hosseinida@yahoo.com DOI: $10.5812 / j j m .3636$ Copyright $\odot 2012$ Kowsar Corp. All rights reserved.
}

devastating consequencessuch as tremendous loss of productivity and further spread of the pathogen in the area. Unlike treatment with antibiotic drugs, which leads to further problems, such as appearance of antibiotic-resistance bacteria, vaccination against infectious disease is the most effective way of reducing or eradicating these diseases.

Cytokines are proteins that have a key role in stimulating the immune system. They can generate a protective immune response as an antibody-mediated (Th2) response or a cell-mediated (Th1) response, based on their combination (1). Therefore, the use of cytokines as novel vaccine adjuvants has been well investigated (2). Further, IL-2, a well-known cytokine, has attracted much interest 
due to its pleiotropic characteristics and vital role in activating T-cell proliferation (3).

The stimulation and differentiation of T cells, B cells, NK cells, lymphokine-activated killer (LAK) cells, monocyte/macrophages, and neutrophils (4-6) are wellknown. Many immunosuppressive avian pathogens, such as IBDV (7), Marek's disease virus (8), Newcastle disease virus (9), chicken anemia virus (10), and Eimeria tenella (11), interfere with the induction of chIL-2 in vivo or cause its abnormal production. This suggests that chIL-2 may be important for the control of these diseases (12). The aim of this study was to extract and sequence Iranian chicken IL-2.

\section{Materials and Methods}

\subsection{Chicken}

Outbreak inbred Iranian chickens were bred at the Razi Institute. Newlyhatched chickens were housed in wire-floor cages with free access to food and water. They were immunized against IBDV disease virus on the day of hatching. Thirty-day-old Iranian chickens were used for this study.

\subsection{Isolation of Splenic Mononuclear Cells (SMCs)}

Spleens from 4-week-old Iranian chickens were collected aseptically into RPMI 1640 medium (Invitrogen). Spleen tissue was minced using a pair of sterile scissors and passed through a steel mesh to obtain a homogeneous cell suspension. The cells were pelleted by centrifugation at 13,000 rpm for $5 \mathrm{~min}$ at $4^{\circ} \mathrm{C}$ and washed twice in RPMI 1640 medium (Gibco) with EDTA $2.5 \%$. Cell suspensions were then overlain on an equal volume of Histopaque-1077 (Sigma). The interface, rich in mononuclear cells, was recovered after centrifugation at $1500 \times \mathrm{g}$ for 15 min at $4^{\circ} \mathrm{C}$. Cells were washed twice in serum-free RPMI 1640 and centrifuged at $1300 \times \mathrm{g}$ for $5 \mathrm{~min}$ at $4^{\circ} \mathrm{C}$. After being assessed for cell viability by Trypan blue dye exclusion technique, the cells were resuspended at a concentration of $10^{7}$ cells $/ \mathrm{ml}$ in RPMI 1640 (containing $1 \%$ l-glutamine, 2 $\mathrm{mg} / \mathrm{ml}$ fetal serum albumin, $1 \mathrm{U} / \mathrm{ml}$ penicillin, and $1 \mathrm{mg} /$ $\mathrm{ml}$ streptomycin). Then, the cells were cultured in 6-well plates and stimulated with ConA at a final concentration of $10 \mu \mathrm{g} / \mathrm{ml}$ at $40^{\circ} \mathrm{C}$ in a humidified atmosphere with $5 \%$ $\mathrm{CO} 2$.

\subsection{RNA Isolation and RT-PCR}

The cells were harvested, and total RNA was isolated with Trizol reagent (Invitrogen) at 18, 24, 36, and $48 \mathrm{~h}$ after ConA stimulation. Briefly, Trizol $(750 \mu \mathrm{l})$ was added to cells, mixed thoroughly, and incubated for $5 \mathrm{~min}$ at room temperature (RT); $200 \mu \mathrm{l}$ chloroform was added, mixed, and incubated for $5 \mathrm{~min}$ at room temperature. Then, centrifugation was carried out at $1200 \mathrm{~g}$ for $20 \mathrm{~min}$ at $4^{\circ} \mathrm{C}$. Total RNA in the aqueous phase was precipitated with $800 \mu$ isopropanol, and the RNA pellet was washed with
$75 \%$ ethanol, air dried, and resuspended in $50 \mu$ nuclease-free water. To determine the full coding sequence of chIL-2, forward (5'- CTAGAATTCGATAACTGGGACACTG-3') (with EcoRI site underlined) and reverse primer (5'- GTCAAGCTTCAACGTACATTTTGAG-3') (with HindIII site underlined) were designed based on published sequences of chicken IL-2 (GenBank Accession No. AF000631), and cDNA was synthesized from total cellular RNA by one-step RT-PCR.

RT-PCR of chicken IL-2 (chIL-2) gene was performed in a 25- $\mu$ l reaction for each mRNA sample containing $5 \mathrm{pmol}$ of F-primer, 5 pmol of R-primer, $5 \mu \mathrm{l} \mathrm{AMV/Tf1} \mathrm{Buffer} \mathrm{(5x),}$ $3 \mu \mathrm{l} \mathrm{MgSO} 4$ (25mM), $0.5 \mu \mathrm{l}$ dNTP Mix (10 mM), 0.5 polymerase ( $5 \mathrm{~m} \mu \mathrm{l}-1)$ (Promega), $12 \mu \mathrm{l}$ nuclease-free water, and $300 \mathrm{ng}$ mRNA. The amplification program was as follows: $45^{\circ} \mathrm{C}$ for $45 \mathrm{~min} ; 5 \mathrm{~min}$ at $95^{\circ} \mathrm{C} ; 35$ cycles of $30 \mathrm{~s}$ at $95^{\circ} \mathrm{C}$ for denaturation, $50 \mathrm{~s}$ at $55^{\circ} \mathrm{C}$ for annealing, and $1 \mathrm{~min}$ at $72^{\circ} \mathrm{C}$ for elongation; and $72^{\circ} \mathrm{C}$ for 10 min for prolonged elongation. The expected 668-bp PCR product was by electrophoresis of $4 \mu \mathrm{l}$ of the total PCR reaction volume on a $1 \%$ agarose (TAE) gel.

\subsection{T/A Cloning of Chil-2 Gene}

The desired 668-bp fragment was cloned into the PTZ57R/T vector using the TA cloning kit (Fermentas) with $3 \mu$ PTZ57R/T vector, $6 \mu$ l Ligation Buffer (5x) (30 mM Tris-HCl pH 7.8, 10 mM MgCl2, 10 mN DTT, $200 \mu \mathrm{M}$ ATP, 5 $\%$ polyethylene glycol), $1 \mu$ T T4 DNA Ligase (Promega), 18 $\mu \mathrm{l}$ nuclease-free water, and $200 \mathrm{ng}$ PCR. Ten microliters of ligation mix was added to $150 \mu$ l of Escherichia coli Top10 competent cells and incubated on LB Agar plates (Merck) containing $50 \mu \mathrm{g} / \mathrm{ml}$ ampicillin, $100 \mathrm{mM}$ IPTG, and $20 \mathrm{mg} /$ $\mathrm{ml} \mathrm{X-Gal} \mathrm{overnight} \mathrm{at} 37^{\circ} \mathrm{C}$. White colonies were selected and checked for the presence of the insert by PCR.

\subsection{Screening of Transformed Colonies}

PCR was performed to confirmthe desired gene in the $\mathrm{T} / \mathrm{A}$ vector in the selected colonies. PCR-positive colonies were grown overnight in $4 \mathrm{ml}$ of LB medium containing $50 \mu \mathrm{g} / \mathrm{ml}$ ampicillin. Plasmid DNA was extracted and purified from $4 \mathrm{ml}$ of bacterial suspension following the instructions of the Fermentase mini-prep kit. Also, the transformants were confirmed by RE analysis with EcoRI and HindIII at $37^{\circ} \mathrm{C}$ for $5 \mathrm{~h}$. The recombinant plasmids were sequenced by Millegene (France). BLAST was used to compare the nucleotide sequences and the registered computational chicken sequence at NCBI (accession number AF000631).

\section{Results}

\subsection{Isolation SMC, RNA and RT-PCR}

Based on the chIL-2 sequence published by Sundick and Gill-Dixon (1997) (3), 2 primers that spanned the coding region of chIL-2 were designed with restriction sites. Isolation of lymphocytes from the culture and ConA-activat- 
ed spleens from Iranian chickens, followed by extraction of total RNA and RT-PCR, resulted in the synthesis of a 668-bp DNA fragment after $18 \mathrm{~h}$ of culture. After RT-PCR, a distinct 668-bp band appear that was related to the IL-2 gene (Figure 1)

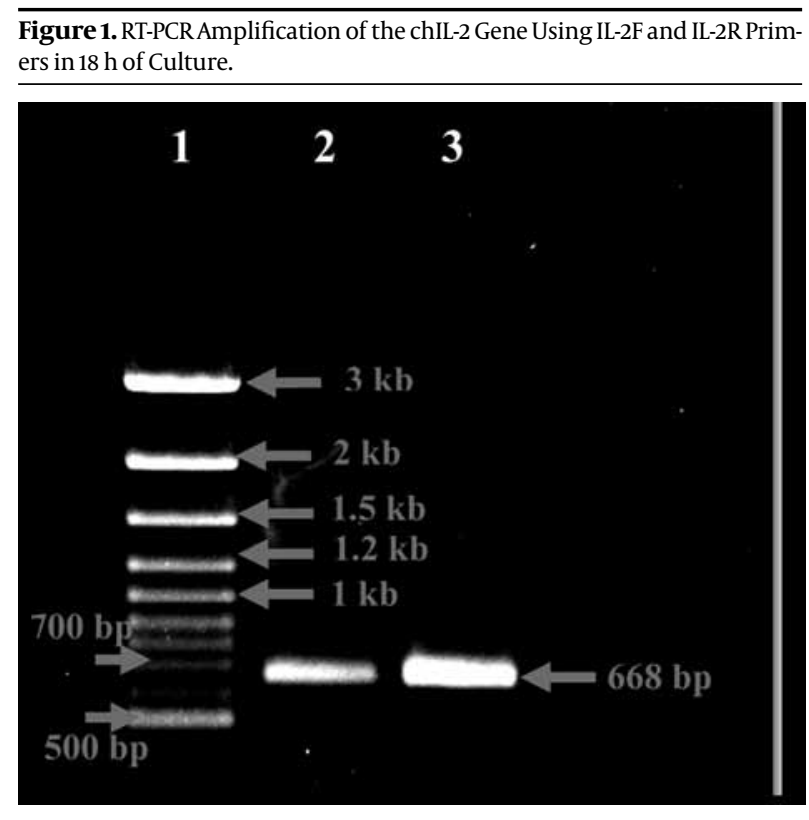

Lanes 2 and 3 are the Same PCR Products and Lane 1 is DNA Ladder of $1 \mathrm{~Kb}$.

\subsection{Screening of Transformed Colonies}

The amplified PCR product was cloned into the T/A vector and transformed into competent E. coli Top10.White colonies (with the insert) were chosen and checked for the

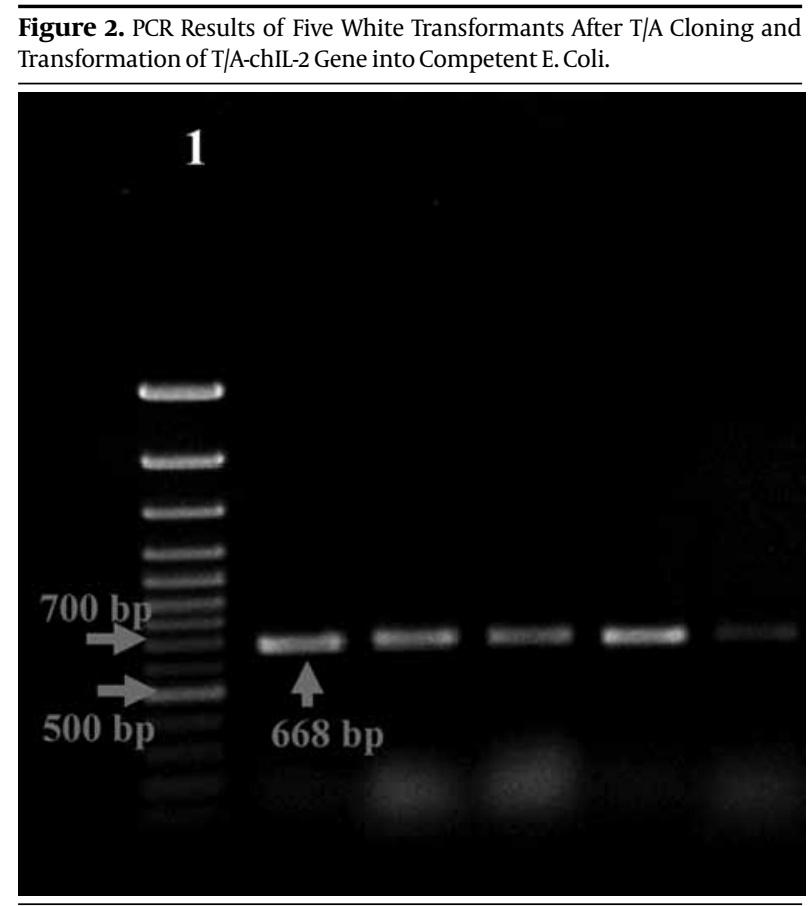

Lane 1 is 100 bp DNA Ladder. presence of the insert by colonyPCR. The amplification reaction contained $5 \mu \mathrm{l}$ Tf1 Buffer, $3 \mu \mathrm{l} \mathrm{MgSO} 4$, 0/5 $\mu \mathrm{ldNTP}, 5$ pmol primer-F, 5 pmol primer-R, 0/5 $\mu$ Tffi DNA polymerase, $10 \mu \mathrm{H} 2 \mathrm{O}$ (nuclease-free), and transformed colony as DNA template. Figure 2 shows the results of the colonyPCR.

Extraction of T/A-IL-2 plasmid and agarose gel electrophoresis generated a band, and digestion of this purified recombinant plasmid with restriction enzymes showed 2 distinct bandschIL-2 gene and TA plasmid (Figure 3). By sequence comparison with chicken IL-2, the 668-bp PCR product was the intended gene, with $99 \%$ identity. The entire sequenced Iranian chicken interleukin-2 gene is shown in Figure 4.

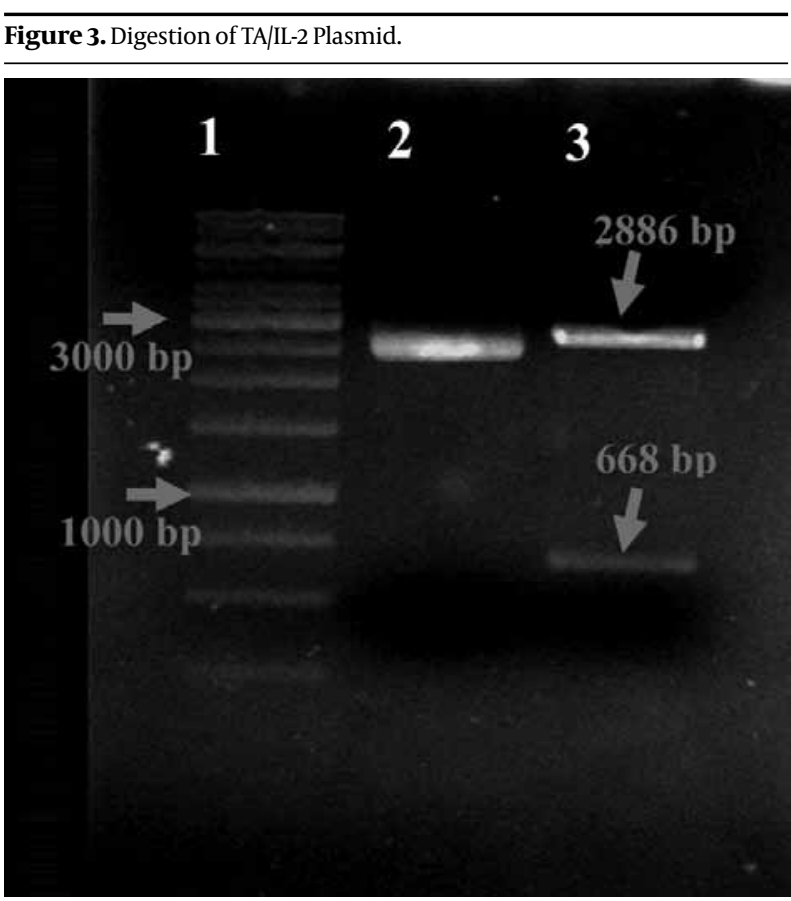

Lane 1: 1 kb DNA Ladder, lane 2 Uncut Extracted TA/IL-2, Lane 3: Digested TA/IL-2 With EcoRI and HindIII, yielding fragments of 2886 bp(TA) and 668 bp (chIL-2)

Figure 4. Sequence of Iranian Chicken Interleukin-2 Gene. Restriction Enzymes are Indicated in Bold Capital Letters.

NNNNNNNGGATCCGATTCTAGAATTCGATAACTGGGACACTGCCATGA TGTGCAAAGTACTGATCTTTGGCTGTATTTCGGTAGCAATGCTAATGAC TACAGCTTATGGAGCATCTCTATCATCAGCAAAAAGGAAACCTCTTCA AACATTAATAAAGGATTTAGAGATATTGGAAAATATCAAGAACAAGAT TCATCTCGAGCTCTACACACCAACTGAGACCCAGGAGTGCACCCAGC AAACTCTGCAGTGTTACCTGGGAGAAGTGGTTACTCTGAAGAAAGAA ACTGAAGATGACACTGAAATTAAAGAAGAATTTGTAACTGCTATTCAA AATATCGAAAAGAACCTCAAGAGTCTTACGGGTCTAAATCACACCGG AAGTGAATGCAAGATCTGTGAAGCTAACAACAAGAAAAAATTTCCTG ATTTTCTCCATGAACTGACCAACTTTGTGAGATATCTGCAAAAATAAG CAACTAATCATTTTTATTTTACTGCTATGTTATTTATTTAATTATTTAATTA CAGATAATTTATATATTTTATCCCGTGGCTAACTAATCTGCTGTCCATTC TGGGACCACTGTATGCTCTTAGTCTGGGTGATATGACGTCTGTTCTAAG ATCATATTTGATCCTTTCTGTAAGCCCTACGGGCTCAAAATGTACGTTG AAGCTTACAATCTAGATGCNNNNNNNNNNNN

The Translation Start Codon, ATG, and the Termination Codon, TAA, are Underlined. 


\section{Discussion}

Immune cytokines, such as chIL-2, are being incorporated into vaccination regimens by the poultry industry and could potentially act as natural vaccine-enhancing molecules (13). IL-2 is a nonantigen-specific lymphokine produced by $\mathrm{T}$ lymphocytes following antigenic stimulation (14). This lymphokine is essential for T lymphocyte proliferation (15), differentiation of B lymphocytes into plasma cells (16), and cloning of antigen-specific T lymphocytes (17). IL-2 has come to be recognized as an important immunoregulatory molecule because of its various functions (14).

In the present study, based on the chIL-2 sequence published by Sundick and Gill-Dixon (1997), 2 specific primers were designed to span the coding region of chIL-2. Our group isolated lymphocytes from spleen cell cultures of 4-week chickens, versus other studies that used bloodextracted leukocytes, such as Hulse et al. (2004), who extracted chIL-2 from peripheral blood isolated by Histopaque 1077 by piercing the hearts of 8-week-old chickens (13). Also, Kumar et al. (2009) used white blood cells obtained by Histopaque 1077 (18). To isolate the leukocytes of peripheral blood, we used Ficoll. Our results are in good agreement with those of Kogut (2003) (19), Choi (2003) (11), and Li (2004) (12). However, Hulse (2004), Kumar (2009), and Zhou (2005) used Histopaque 1077 as an alternative for Ficoll $(13,18,20)$.

The RT-PCR at a $55^{\circ} \mathrm{C}$ annealing temperature generated a 688-bp band of the chIL-2 gene after only 18 hours of culture, and no band was detected at 24,36 , or 48 hours. This is noteworthy, because the length of genes reported in other studies have varied, depending on primer design. We used Hindi III and EcoRI, unlike other reports.

Here, after performing gradient RT-PCR using specific primers and transferring the product to a $1 \%$ TAE agarose gel, we observed a 688-bp band of chIL-2. To grow the PCR product, it was ligated into thePTZ57R/T vector, which is an appropriate system for direct one-step cloning of PCRamplified DNA fragments, with a typical yield of greater than $90 \%$. Our sequencing results of Iranian chIL-2 show that full-length chIL-2 cDNA is $668 \mathrm{bp}$, encoding a 143-amino-acid precursor. To determine whether this nucleotide sequence has shared identity with any known or characterized nucleotide sequences, sequence analysis was performed using GenBank. The analysis identified chIL-2 as a member of the IL-15 superfamily. Iranian chIL-2 shares 58 \% homology with duck IL-2, 80 \% homology with turkey IL2 , and $41 \%$ homology with mammalian IL-2. Against other NCBI-published chIL-2sequences, our Iranian chIL-2 was $100 \%$ identical to the Chinese breed broiler and UK chIL2 genes. Furthermore, $99 \%$ identity was seen with the US, Chinese chengren, and leghorn chIL-2 gene. Further analysis showed that Iranian chIL-2 shares $98 \%$ homology with the Chinese breed Xianju and Indian morghi and 97 $\%$ with the Chinese breed silky. Analysis of the predicted amino acid sequence suggests that the overall protein structure is conserved.For the first time, in the present study, Iranian chIL-2 was extracted, and the similarities and differences were studied. Further studies should produce Iranian chIL-2 recombinant protein and studypotential in both DNA and recombinant vaccines. We conclude that systemic use of IL-2 enhances protection significantly, which correlates with intensified cellular responses, rather than antibody-mediated protection.

\section{Acknowledgments}

None declared.

\section{Financial disclosure}

None declared

\section{Funding/Support}

Razi vaccination and serum research institute, Arak, Iran

\section{References}

1. Mosmann TR, Sad S. The expanding universe of T-cell subsets: Th1, Th2 and more. Immunol Today.1996;17(3):138-46.

2. Husband AJ, Bao S, Muir W, Ramsay AJ, Ramshaw IA. Cytokine regulation of mucosal responses: a rational basis for new vaccine delivery strategies. Reprod Fertil Dev. 1994;6(3):381-8.

3. Sundick RS, Gill-Dixon C. A cloned chicken lymphokine homologous to both mammalian IL-2 and IL-15. J Immunol. 1997;159(2):720-5.

4. Atkins MB, Mier JWT. herapeutic Applications of Interleukin-2. In: Dekker M, editor. genitourinary oncology. 1st ed. New York; 1993.

5. Schumann RR, Nakarai T, Gruss HJ, Brach MA, von Arnim U, Kirschning C, et al. Transcript synthesis and surface expression of the interleukin-2 receptor (alpha-, beta-, and gamma-chain) by normal and malignant myeloid cells. Blood. 1996;87(6):241927.

6. Bartlett Y. Potential monitoring value of functional interleukin-2 receptors on human neutrophils. Clin Diagn Lab Immunol. 1998;5(2):270.

7. Wu CC, Dorairajan T, Lin TL. Effect of ascorbic acid supplementation on the immune response of chickens vaccinated and challenged with infectious bursal disease virus. Vet Immunol Immunopathol. 2000;74(1-2):145-52.

8. Xing Z, Schat KA. Expression of cytokine genes in Marek's disease virus-infected chickens and chicken embryo fibroblast cultures. Immunology. 2000;100(1):70-6.

9. Thiagarajan D, Ram GC, Bansal MP. Optimum conditions for in vitro chicken IL-2 production and its in vivo role in Newcastle disease vaccinated chickens. Vet Immunol Immunopathol. 1999;67(1):79-91.

10. Markowski-Grimsrud CJ, Schat KA. Infection with chicken anaemia virus impairs the generation of pathogen-specific cytotoxic T lymphocytes. Immunology. 2003;109(2):283-94.

11. Choi KD, Lillehoj HS. Role of chicken IL-2 on gammadelta T-cells and Eimeria acervulina-induced changes in intestinal IL-2 mRNA expression and gammadelta T-cells. Vet Immunol Immunopathol. 2000;73(3-4):309-21.

12. Li J, Liang X, Huang Y, Meng S, Xie R, Deng R, et al. Enhancement of the immunogenicity of DNA vaccine against infectious bursal disease virus by co-delivery with plasmid encoding chicken interleukin 2. Virology. 2004;329(1):89-100.

13. Hulse DJ, Romero $\mathrm{CH}$. Partial protection against infectious bursal disease virus through DNA-mediated vaccination with the VP2 cap- 
sid protein and chicken IL-2 genes. Vaccine. 2004;22(9-10):1249-59.

14. Robb RJ. Interleukin 2: the molecule and its function. Immunology Today. 1984;5(7):203-9.

15. Gillis S, Smith KA. Long term culture of tumour-specific cytotoxic T cells. Nature. 1977;268(5616):154-6.

16. Howard M, Matis L, Malek TR, Shevach E, Kell W, Cohen D, et al. Interleukin 2 induces antigen-reactive T cell lines to secrete BCGF-I. J Exp Med. 1983;158(6):2024-39.

17. Gillis $S$, Watson J. Interleukin-2 induction of hapten-specific cytolytic T cells in nude mice. J Immunol.1981;126(4):1245-8.

18. Kumar S, Ahi YS, Salunkhe SS, Koul M, Tiwari AK, Gupta PK, et al.
Effective protection by high efficiency bicistronic DNA vaccine against infectious bursal disease virus expressing VP2 protein and chicken IL-2. Vaccine. 2009;27(6):864-9.

19. Kogut MH, Rothwell L, Kaiser P. Priming by recombinant chicken interleukin-2 induces selective expression of IL-8 and IL-18 mRNA in chicken heterophils during receptor-mediated phagocytosis of opsonized and nonopsonized Salmonella enterica serovar enteritidis. Mol Immunol. 2003;40(9):603-10.

20. Zhou JY, Wang JY, Chen JG, Wu JX, Gong H, Teng QY, et al. Cloning, in vitro expression and bioactivity of duck interleukin-2. Mol Immunol. 2005;42(5):589-98. 